\title{
Principles of Blood Transfusion
}

\author{
Nuri Mamak and İsmail Aytekin
}

Additional information is available at the end of the chapter

http://dx.doi.org/10.5772/48332

\section{Introduction}

The aim of this chapter is to present a revised overview of small and large animal transfusion medicine based on a review of the veterinary literature. Blood transfusion has become more performable in small and large animal practice. By donor selection and the availability of blood component substitutes, usage of the blood products improved. The use of blood component therapy safely needed knowledge of blood groups, antibody prevalence and the impact of blood groups on veterinary transfusion medicine. Animal blood transfusions antibodies against blood group antigens also play a role. In addition knowledge of the means to decrease the risk of adverse reactions by using proper donors and screening assays that simplify detection of serological incompatibility is important. The clinical significance of blood group antigens in veterinary medicine is generally in the areas of transfusion reactions and neonatal isoerythrolysis (NI). This chapter includes an update on canine and feline, horse, donkey, cattle, sheep, gaot, pig, llama and alpaca blood groups and known blood incompatibilities, donor selection and blood collection, storage of blood components, available equine blood products and indications for transfusion, whole blood (WB) and blood product transfusion in ruminants and camelids, blood component and blood substitute therapy, administration, and adverse reactions in small and large animal blood transfusion.

\section{Blood types in dogs and cats}

Blood types are classified according to specific antigens on the surface of erythrocytes. Platelets, leukocytes, and body tissues and fluids may also consists of erytrocyte antigens. [1]. In immunogenicity and clinical significance these antigens can differ. They can serve as markers of disease in some cases and taking part in recognition of self. The clinical significance of blood group antigens is generally noted in transfusion reactions and neonatal isoerythrolysis (NI) in veterinary medicine [2]. These antigens can characteristically trigger a reaction caused by circulating anti-erythrocyte antibodies in the opposite host or donor. 
These antibodies can occur naturally. Also they can be induced by a previous transfusion. Interaction leads to the destruction by hemolysis of red blood cells (RBCs). This is one of the severe and potentially life-threatening situation. [3].

The dog erytrocyte antigen types or blood types are categorized by the DEA (Dog Erythrocyte Antigen) system. DEA 1.1, 1.2, and 1.3 are termed A system. There are also DEA 3, DEA 4, DEA 5, DEA 6, DEA 7 and DEA 8. [2]. In the United States the incidence of DEA 1.1 is approximately $45 \%$ and DEA 1.2 is $20 \%$ [4]. DEA 1.3 is common in German shepherd dogs and has been reported only in Australia [5]. Frequency of DEA 1.1 in Kangal Dog was found as $61.1 \%$ in Turkey [6]. In Croatia where the closest data studied the rate was $66.7 \%$ [7]. The rate was also 56.9\% in Portugal [8] and 55\% in Japan [9]. Approximately $60 \%$ of the canine population is in DEAs 1.1 and 1.2 group. DEA 1.1 is the strongest antigen in the dog. Two membrane proteins of 50 and $200 \mathrm{kD}$ has been identified by a monoclonal antibody to DEA 1.1 using immunoprecipitation techniques. [10]. Presenting in a single band DEA 1.2 has been found to be an $85-\mathrm{kD}$ protein [11].

DEA 1.1 is the most antigenic group in respect to transfusion medicine. Little is investigated about DEA 3, 4, 5 and 7 in comparison to DEA 1.1. In literature, the frequency of DEA 3 is lower in comparison to DEA 1.1 blood type. In the United States it is determined that approximately $6 \%$ of the general dog population is DEA 3 positive [12]. This rate is reported as $13 \%$ in Brazil [13]. In Turkey, DEA 3 is most found blood type in the Kangal Dog [6]. In the canine blood groups DEA 4 is the most common type. In USA, it is indicated that overall $98 \%$ of the general dog population have DEA 4 blood [12]. In Brazil, all dogs blood type were positive for DEA 4 [13]. The molecular weight of DEA 4 present in a single band has been found to be 32 to $40 \mathrm{kD}$ using immunoprecipitation techniques [11].

In the United States typing sera can be commercially obtained only for DEA 1.1, 1.2, 3, 4, 5, and 7 [4]. In Brazil a report studied on German shepherd dogs determined that $14 \%$ of the dogs were positive for DEA 5 and $8 \%$ were positive for DEA 7 [13]. The frequency of DEA 5 and 7 positive dogs was $55.5 \%$ and $71.7 \%$ respectively in Turkey [6]. Also, DEA 7 may cause an antibody response in dogs that lack it. A system of nomenclature about antigen $\operatorname{Tr}$ has described. The Tr antigen system is a 3-phenotype, 6-genotype system [14]. The molecular weight of DEA 7 present in 3 distinct bands has been found to be 53,58, and $63 \mathrm{kD}$ by using immunoprecipitation techniques [11].

An exact definition of a canine universal donor is not agreed among veterinary transfusion experts. Well excepted description of the universal donor is that a dog negative for DEA 1.1, 1.2, DEA 3, DEA 5, DEA 7, and positive for DEA 4 . It is difficult to find DEA 4 negative dog because $98 \%$ of all dogs are positive for DEA 4 . Thus there is a very little chance to influence donor selection. If the dog is DEA 7 positive, some other experts do not exclude it from the donor pool [15]. In most populations the incidence of DEA 4 blood type is more than $98 \%$ [16]. Because of this in transfusion medicine these dogs are the best candidate for being a donor. If other donors are known to be compatible with the recipient they can also be utilized [17]. DEA 3, 5 and 7 negative dogs have naturally occurring antibodies to DEA 3, 5 and 7 positive red cells. However during the first transfusion these blood groups do not 
possess a major transfusion reaction [4]. In Turkey, the most common blood types were DEA 1.1, 4 and 7. Because all Kangal dogs have DEA 4 positivity it does not seem to be important in respect to transfusion medicine. The prevalence and antigenic properties of DEA 1.1 and 7 are significantly important. If unmatched transfusion is performed in Turkish Kangal dogs they can constitute acute hemolytic transfusion reactions [6]. Dogs with DEA 1.1 or 1.2 are called group A positive. Adversely, dogs do not have DEA 1.1 or 1.2 are called group A negative [1].

A blood group system described as $\mathrm{N}$-acetylneuraminic acid and $\mathrm{N}$-glycolylneuraminic acid present on gangliosides (hematosides) of the RBC membrane in Japan [18]. It is referred as the D system. This system is consist of two antigens, D1 and D2, with phenotypes, D1, D2, and D1D2. The D1 and D2 antigens are codominanat factors. Anti-D1 is identical to antiDEA3. The importance of this system in transfusion medicine pointed out by transfusion of D2 type blood into a D1 type patient, or of D1 type blood into a D2 type patient consistently cause severe acute transfusion reactions $[19,20]$. RBCs of some dogs designated as type $C$ at titre sup to 128 are aglutinated rather than lectin extracted from seeds of Clerodendron tricotomum. Type $C$ is completely negative for other dogs. $C$ system was compared to the DEA system and determined to be different [10, 19, 21]. Specific IgG alloantibodies in previously sensitized Dalmatian dog by blood transfusion is described as the Dal blood type. The frequency is not known. Typing sera for this antigen also is commercially not available $[2,22,23]$.

Three blood types are described in the feline AB blood group system and mik group system. In cats a new blood group defined as Mik. It is named after the alloantibody identified in the first blood donor cat, Mike. In three cats that had not previously received transfusions Mik antibodies were detected. They are defined as a cause of incompatibilities between donor and recipient blood that are not related to the AB blood group system [24].

The phenotypes type A, type $B$, and type $A B$ are occured. A null phenotype is not exist. The most common blood type is Type A. Type B is less common. Type AB is rare $[2,25]$. Type $B$ is indicated in Australia (26.3\%), and Greece (20.3\%) ([26] , [27] ). In large studies of both pedigree and non-pedigree cats in the USA distribution of type AB cats is demonstrated to be rare $(0.14 \%)([28])$. Type AB were $0.4 \%$ in Australia (([26]). In Scotland the incidence of $\mathrm{AB}$ cats is $4.4 \%$ ([29] ).

Type B is indicated in Australia (26.3\%), and Greece (20.3\%) ([26, 27]. In large studies of both pedigree and non-pedigree cats in the USA distribution of type $A B$ cats is demonstrated to be rare $(0.14 \%)$ [28]. Type AB were $0.4 \%$ in Australia [26]. In Scotland the incidence of AB cats is $4.4 \%$ [29].

In Turkey, $60 \%$ of Van cats and $46.4 \%$ of Angora cats are type B [30]. And $220(73.1 \%)$ nonpedigree domestic cats had type A blood, 74 (24.6\%) had type B and seven (2.3\%) had type $\mathrm{AB}[31]$ in Turkey. Except type $\mathrm{AB}$ group, cats have naturally occurring alloantibodies. It is known that cats have naturally occurring alloantibodies (isoantibodies) against the blood type they are lacking. Because of this to prevent blood incompatibility reactions in cats feline blood typing is important in clinical practice. Blood type incompatibility can 
especially result in two fatal reactions. The first is acute haemolytic transfusion reactions, occur particularly in cat transfused with type A blood [32]. Feline neonatal isoerythrolysis (NI) is the second incompatibility reaction. It occurs when type A or AB kittens born to type B queens are nursing. Naturally occurring anti-A alloantibodies result in blood incompatibility reaction in the type B queen's colostrum and milk $[25,30]$.

Cats constitute non-self antibodies in contrast to dogs. As a result of this non-self antibodies potentially fatal antibody-mediated reactions can occur towards non-self red blood cells. Nearly $20 \%$ of type A cats have anti-B antibodies. These antibodies are usually weak. All type $B$ cats have strong anti-A antibodies. In contrast AB cats do not have alloantibodies [32]. In previously unsensitized cats naturally occuring isoantibodies are responsible for transfusion reactions. Nearly all type B cats have highly titered anti-A agglutinins and hemolysins. RBCs can be destructed rapidly in type B cats taking type A blood. In type B cats the high titres of naturally occurring anti-A antibodies cause rapid intravascular destruction of transfused type A red blood cells [33]. This can be mediated by IgM, complement fixation and the release of potent vasoactive compounds. As a result of this shock can develop usually due to possessed antibodies towards the transfused RBCs [3, 34]. This can cause severe transfusion reaction and death even if as little as $1 \mathrm{ml}$ of type A blood is administered to a type B-cat $[2,35]$. Because of their endotheliochorial placenta newborn kittens have no alloantibodies. Nevertheless colostral transfer of immunoglobulin (Ig) G and a small amount of IgM occurs. Neonatal isoerythrolysis develops in cats. It is one of the cause of the fading kitten syndrome. Kittens that are type $\mathrm{A}$ or $\mathrm{AB}$ and those that are born to type $B$ queens are at risk. In affected kittens Clinical sings can range from unapparent, to severe hemolytic anemia with hemoglobinuria, icterus, and death $[1,36,37,38]$.

\section{Transfusion therapy}

Packed red blood cells (pRBCs) and fresh frozen plasma (FFP) are components generally provided for canine transfusions. If processed at once, 1-4 each unit $(450 \mathrm{~mL})$ of whole blood can be seperated into 1 unit of pRBCs and 1 unit of FFP. It is difficult to prepare components from a small volume of blood. Because of this cat blood transfusions are usually administered as fresh or stored whole blood. If patients requires specific components like pRBCs and FFP, in this case whole blood can be separated into them [39].

In veterinary medicine, red blood cell transfusions are used more frequent recently. They are the integral part of lifesaving. They are used in critically ill as advanced treatment. Situations required transfusions include life-threatening anemia from acute hemorrhage or surgical blood loss, hemolysis from drugs or toxins, immune-mediated diseases, severe nonregenerative conditions, and neonatal isoerythrolysis [40].

Indications of red blood cell transfusions are in the treatment of anemia caused by hemorrhage, hemolysis, or ineffective erythropoiesis. Oxygen is poorly soluble in plasma. Because of this oxygen in blood is mostly carried by hemoglobin (Hgb). In anemic patient, RBC transfusions increase the oxygen-carrying capacity. Therefore inadequate delivery of oxygen to tissues with consequent tissue hypoxia are prevented or treated [41]. 
The treatment of severe anemia caused by hemorrhage, hemolysis, ineffective erythropoiesis, auto-immune hemolytic anemia, or neoplasia is primary indication for blood transfusion. Lethargy and altered mentation, increased respiratory effort, pale mucous membranes and tachycardia are the clinical signs of anaemia. The body carry out a number of adaptive responses physiologically, to maintain carrying of oxygen to the tissues [42, 43]. The solution of oxygen in plasma is weak. Because of this hemoglobin (Hgb) carries approximately whole oxygen in blood [41]. The decision to conduct a RBC transfusion is generally based on a measurement of the patient's packed cell volume (PCV), hematocrit (Hct) or Hgb concentration $(\mathrm{Hgb})$ and especially on clinical evaluation of the patient [41]. Clinically animals should be evaluated individually. Generally when the hematocrit is less than $10 \%$, the treatment of anemia is transfusion. However, animals with acute-onset anemia usually require transfusion before their hematocrit decreases to $15 \%$. This contrasts with the situation in animals with chronic anemia. Other indications for transfusion are hypovolemia, thrombocytopenia, clotting factor deficiency, and hypoproteinemia [1]. Electrocardiographic signs of myocardial ischaemia are similar to those identified in human patients with myocardial infarction. It can ocur with anemia [44].

The usage of administration of FFP are for the treatment of a single or multiple clotting factor deficiency, vitamin $\mathrm{K}$ deficiency or antagonism, surgical bleeding or where a massive transfusion is required [45]. Hypoalbuminaemia and coagulopathies especially due to liver disease are the main reported indications for FFP transfusions in cats [46].

Stored blood is more than 8 hours old. The length of storage depends on the anticoagulant/preservative solution used. It varies from 48 hours for $3.8 \%$ sodium citrate (no preservative) to 4 weeks for CPD-A1 (citrate, phosphate, dextrose, and adenine). Acid citrate dextrose (ACD), citrate phosphate dextrose (CPD and CP2D), and citrate phosphatedextrose-adenine (CPDA-1) are mostly used as preservatives. The viability of RBCs is provided by the added dextrose, phosphate, and adenine. Due to the preservative used, the storage can extend up to 3 to 5 week $([3,41,47]$.

In patients that are hypothermic or receiving large volumes of blood, refrigerated RBC products should be prewarmed to temperatures between $22^{\circ} \mathrm{C}$ and $37^{\circ} \mathrm{C}$ immediately before transfusion. In the routine practice of RBC products to normovolemic anemic patients, refrigerated blood components do not need warming before transfusion. Warming may accelerate the deterioration of stored RBCs and may cause rapid growth of contaminating microorganisms [48].

In clinical practice advances in safety of blood transfusion is important in preventing transfusion-transmitted infections (TTI). The most frequent severe infectious outcome of transfusion has been known as bacterial contamination of platelets, with resultant sepsis in the recipient recently. Using automated or semi-automated blood culture devices, apheresis platelets and prestorage pooled platelets are most often tested [49].

Generally, before a blood transfusion is given to animals, blood typing and/or crossmatching of the recipent and donor should be done to avoid the likelihood of a transfusion reaction. Also, ineffective therapy is caused by shortened survival of transfused mismatched 
red cells. In order to prevent primary sensitization and risk of developing hemolytic disease in breeding females, cross-matching and/or blood typing is important. In general veterinary practise, blood typing for canine DEA 1.1 and for feline types A and B is applied [1].

To decrease adverse reactions one sould pay attention to blood typing and crossmatching procedures as much as monitoring. There is always risk in blood transfusions. For this reason, they should be performed only when warranted. When taking history, previous transfusion therapy should be asked and in a history of previous transfusion therapy crossmatching is necessary $[1,50]$.

Depending on availability and indication for transfusion, whole-blood or blood-component therapy may be administered. RBCs, white blood cells (WBCs), platelets, all the coagulation factors, albumin and immunoglobulins constitute whole blood (WB) [51].

In cats, fresh whole blood is the most common product used recently. Stored whole blood, packed red blood cells and fresh frozen plasma (FFP) are also given as transfusions [45].

The heavier cellular elements from the supernatant plasma are sedimented by centrifugation of whole blood sediments. Due to separation of blood collection within 8 hours all protein activity and concentration are maintained in the plasma. The obtained supernatant usually frozen. For subsequent transfusion, it is stored as fresh frozen plasma (FFP). In addition it can also processed to provide cryoprecipitate and cryosupernatant. It can also be transfused immediately as fresh plasma $[52,53]$. Fresh frozen plasma have to be stored frozen at $-30^{\circ} \mathrm{C}$ before used. Also it should be identified with the donor blood type, name and collection date. Samples thawed and not used sould discarded or stored in a fridge and used within 12-24 $\mathrm{h}$ and should not be refrozen [43].

Recently an ultra-purified polymerised bovine haemoglobin solution is the only commercially available alternative to red cell transfusion (Oxyglobin). It is not licensed in cats but it has been used in treatment of anaemia in cats and also in therapy of carbon monoxide poisoning [54, 55].

Hemostatic protein deficiencies lead to hemorrhagic disorders and the treatment is done principally by plasma components [56]. In animals with von Willebrand disease (vWD) and hereditary coagulation factor deficiencies active hemorrhage is controlled by plasma components. Plasma components are also used for preoperative prophylaxis in these diseases [53].

For preparation of plasma components sterile plastic bags are used. After that they are stored and transferred as frozen in individual boxes. Products have to be stored at $-20^{\circ} \mathrm{C}$ or lower. Just before transfusion they warmed to $37^{\circ} \mathrm{C}$ in a water bath or incubator. Preferred route of administration is the intravenous transfusion of plasma components. If attempts at vascular access have failed, intraosseous transfusion can be used in emergency situations. When acut allergic reactions occur transfusion is stopped and antihistamines and/or shortacting steroids are given $[53,57]$.

Cats have antibodies to non-self blood types within the plasma. Because of this only typespecific plasma should be administered to cats in contrast to dogs. Using one of the 
commercially available systems whole blood can be separated into FFP and packed red cells if it is taken aseptically. The blood spun at $3800 \mathrm{rpm}$ at $10^{\circ} \mathrm{C}$ in a refrigerated centrifuge for 12 mins. Using a plasma extractor the plasma is extracted and stored at $-20^{\circ} \mathrm{C}$ [57].

In hypoalbuminemic dogs and cats, human serum albumin has been used for therapeutic use [58].

\subsection{Platelet transfusion}

Correction of coagulation by fresh platelets are shown by in vitro coagulation studies. Freshly collected platelets correct thrombocytopenia, control associated hemorrhage, and prevent death from bleeding. Hemorrhagic diathesis are prevented by platelet replacement for thrombocytopenia [59].

Severe thrombocytopenia or thrombopathia result in bleeding. Platelet transfusion is used for the control of this bleeding. In veterinary medicine platelet transfusion has been used rarely compared to red blood cell (RBC) and plasma transfusion. In dogs, reports related to platelet transfusion are generally associated with experimental hematopoietic stem cell transplantation. Platelet-rich blood products consist of fresh whole blood (FWB), plateletrich plasma (PRP) and platelet concentrate (PC). They are used for aggressive anticancer therapy and treating complex hematologic disorders. Centrifugation of whole blood constitute platelet-rich plasma (PRP) and centrifugation of platelet-rich plasma constitude platelet concentrates (PC). Platelet activation is induced by centrifugation so that the resuspension of the platelet pellet during PC preparation from dogs is difficult. The preparation efficiency of PC from dogs can be improved by addition of PGE1 in PRP before the centrifugation of PRP. Also therapeutic efficacy of the platelets are maintained. In 10-28 kg body weight dogs plateletpheresis has been used successfully. On the canine donor thrombocytopenia and hypocalcemia are the main adverse effects of plateletpheresis [60-62].

At room temperature (RT) $\left(20-24^{\circ} \mathrm{C}\right)$, PRP and PC can be stored for 5-7 days with continuous or intermittent agitation. At RT FWB can be stored for up to 8 hours. The interest in freezed $\left(4^{\circ} \mathrm{C}\right)$ storage of platelets is increasing because of the increased risk of bacterial proliferation at RT storage. Storage of human PRP and PC are limited to 5 days because of prevention of bacterial proliferation at room temperature [60-63].

Platelet transfusions as with RBC and plasma components should be performed with 170 $\mu \mathrm{m}$ filters standard blood administration sets. Transfusion sets which can bind platelets should be exempt from latex [60].

The most common reaction to PC are febrile reactions. The frequency is decreased by prestorage leukoreduction. In immunocompetent dogs receiving multiple transfusions, alloimmunization to platelet antigens occurs. Leukocyte reduction and ultraviolet B irradiation are recently accepted methods for preventing the development of platelet alloimmunization [64-66]. 
Recently platelet cryopreservation are used to provide long-term storage and immediate availability of platelet products for transfusion. When fresh platelets are unavailable cryopreserved platelets can be activated in vitro and provide therapeutic benefit [63].

\subsection{Granulocyte transfusion}

Granulocyte transfusion can be used as supportive therapy. It is used in patients with lifethreatening neutropenia caused by bone marrow failure or in patients with neutrophil dysfunction. Granulocyte transfusions is shown to be useful in treatment of infections in patients after treatment with high-dose chemotherapy. It is helpful especially in the chemotherapy associated with conditioning for hematopoietic stem cell transplant. By using granulocyte colony-stimulated factors higher doses of granulocytes for transfusion are produced. Thus recently the use of therapeutic granulocyte transfusion has been increased. The outcome of transfusion are effected by the type of infection being treated, the likelihood of recipient marrow recovery, and recipient alloimmunization [67].

In small animals therapeutic granulocyte transfusions have been used especially in experimental models of myelosuppression and neonatal sepsis. In clinical veterinary medicine they have been used rarely. Granulocytes can be used to identify the site of inflammation. Beside leukapheresis, centrifugation of FWB, with or without colloidfacilitated sedimentation, may be used to isolate canine and feline buffy coats. Only sedimentation may also be used in the cat. At RT granulocytes are stored immobil for 24 hours. The dose for beginning is $1 \times 10^{11}$ granulocytes $/ \mathrm{kg}$ in a volume of $15 \mathrm{~mL} / \mathrm{kg}$. It is used once to twice in a day [68-70].

\section{Donor selection}

To select permanent blood donors, blood typing have to be performed. Donors should be healthy young adults. They undergo routine physical check up and hematology and clinical chemistry evaluations are done. They should never taken a blood transfusion and should be free of blood parasites and other infectious diseases [1].

Nulliparous and spayed female dog and cat donors have to be chosen. Blood have be collected via jugular venipuncture aseptically. Acepromazine interferes with platelet function. Because of this donors should not be sedated with it [1].

Every 3 to 4 weeks, dogs can donate between 13 and $17 \mathrm{ml}$ of blood per kilogram of body weight. Features of donors sould include well nourished, supplemented with oral iron, bled less than once per month to prevent iron deficiency, greater than $25 \mathrm{~kg}$, and negative for antigens for DEAs 1.1, 1.2, 3, 5, and 7. Donors should not have heartworm disease, babesiosis, brucellosis, ehrlichiosis, and Rocky Mountain spotted fever. Donors have appropriate neck skin that allows easy entrance to the jugular vein, have a packed cell volume that is at least $0.40 \mathrm{~L} / \mathrm{L}$, have demonstrated a good temperament and be in good physical condition, have no past time history of transfusion or pregnancy, and have got sufficient levels of von Willebrand factor (vWF) [1, 3]. 
The ideal feline blood donors should be healthy, indoor-only cats with an agreeable temperament for easy handling and restraint. Owned pet cats should be donate maximum once every 2 months [43]. The features of feline donor sould be as follows; weigh more than $4.5 \mathrm{~kg}$, have a packed cell volume that is at least $0.35 \mathrm{~L} / \mathrm{L}$, have demonstrated a good temperament, and be in good physical condition [3]. Donor cats can donate between 10 and $12 \mathrm{ml} / \mathrm{kg}$. Adult healthy cats can donate $50 \mathrm{ml}$ every weeks. Donors have to be type A. Type B donors may be demanded depending on breed prevalence and geography. Feline leukemia virus, feline immunodeficiency virus (FIV), feline infectious peritonitis, heartworm disease, and Hemobartonella sp have to be excluded in donor cats [1].

For appropriate care of donors some processes needed. These are current vaccinations, if there is contact with new animals every 6 mo fecal floatation, monitorization of hemogram every year, analysing clinical chemistry, screening for infectious diseases and in the dog preventative heartworm therapy in areas where it is necessary. When blood collection is taken the donor's weight, temperature, and packed cell volume have to be analysed [3, 71]. PCV or $\mathrm{Hb}$ are measured by taking a blood sample. Preferentially cats with a PCV of 30$35 \%$ are used but cats with low-normal PCVs should not be used [43].

In the cat, blood can be taken by using a 19- to 20 gauge needle or butterfly into a syringe via jugular vein venipuncture. The region over the jugular vein is clipped and prepared aseptically and sedation is administered. It is prefered to use a 1:1 combination of ketamine $100 \mathrm{mg} / \mathrm{ml}$ and midazolam $5 \mathrm{mg} / \mathrm{ml}$. It is made up in a small syringe and given intravenously up to a maximum dose of $5 \mathrm{mg} / \mathrm{kg}$ ketamine $(0.1 \mathrm{ml} / \mathrm{kg}$ of combination). Syringe consists of either ACD, CPD, or CPDA- 1 ( $1 \mathrm{~mL} / 9 \mathrm{~mL}$ of blood), or heparin (5 units/mL of blood). Before a preservative solution is used it can be placed in a small blood bag. To access the jugular vein a 19-21G butterfly needle is used. The blood is collected over a total of 1015 mins. At once a maximum of $10-12 \mathrm{ml} / \mathrm{kg}$ blood can be donated. Isotonic crystalloid fluid therapy post-donation at a rate of $60 \mathrm{ml} / \mathrm{h}$ for $3 \mathrm{~h}$ is given to the cat $[3,43]$.

\section{Administration}

Precaution is necessary to prevent damage of the blood product and harm to recipient. Blood typing or crossmatching have to be carried out to provide compatibility before RBC transfusion [41].

Transfusions of red blood cell should be administered through a filter. The filter is arranged to remove clots and particles which are potentially harmful to the patient. Blood infusion sets have in-line filters. These filters trap large cells, cellular debris, and coagulated proteins. The pore size range from $170 \mu \mathrm{m}$ to $260 \mu \mathrm{m}$. A filter may be used to administer $2-4$ units of blood to a patient or for a maximum time limit of 4 hours according to human blood banking standards. High protein concentration at the filter surface and room temperature conditions promote proliferation of any contaminating microorganisms. The rate of flow slowed down by accumulated material. After 5 days or more of refrigerated storage constituted microaggregates composed of degenerating platelets, white blood cells (WBCs), and fibrin strands in blood. They are removed by other blood filters with a pore size of 20-40 
Jim. For transfusions of RBCs primarily microaggregate filters are designed. In administering small volumes of blood $(<50 \mathrm{~mL} \mathrm{WB}$ or $<25 \mathrm{~mL}$ pRBCs) to cats and small dogs a pediatric micro-aggregate blood filter ( 18 um pore size, priming space $<\mathrm{lmL}$ ) is especially helpful. Because of a progressive decrease in pore size due to increased blood filtered larger volumes of blood administration can result in hemolysis [41].

If plasma is taken from blood preservative solutions can be put in. Blood preservative solutions are dextrose, adenine, mannitol, and the sodium chloride. They are necessary for RBCs to carry on their energy metabolism and viability during storage [3]. Canine pRBCs stored in a RBC preservative can be applied directly. Other $\mathrm{pRBC}$ products have to be diluted by putting $10 \mathrm{~mL}$ of saline feline $\mathrm{pRBC}$ or $100 \mathrm{~mL}$ of saline to the blood bag so that the viscosity of the donor blood decreased [41].

In the dog, if sedation is needed, butorphanol $(0.1 \mathrm{mg} / \mathrm{kg} \mathrm{BW}, \mathrm{IV})$ is generally used for sedation. But acepromazine should not be used because it may cause platelet function disturbance [72]. In the cat, ketamin may be used 2 to $4 \mathrm{mg} / \mathrm{kg} \mathrm{BW}$, IV for sedation. In addition to ketamin is very successful when it is used together with 0.1 to $0.2 \mathrm{mg} / \mathrm{kg}$ BW diazepam [3]. Also combinations of ketamine hydrochloride, midazolam and butorphanol tartrate, or mask administration of sevoflurane can be used [73, 74].

Generally, intravenous administration is used for RBC transfusions. In addition intraosseous administration is a perfect alternative. Peripheral veins may be preferred to central veins because of an increased bleeding predisposition [41].

Blood is administered through administration sets containing $0.9 \%$ saline intravenously. Contraindications include hypotonic saline, 5\% dextrose in water and lactated Ringer's solution. Cardiac arrest may be caused by injection of undiluted citrate containing anticoagulants [1].

Using a syringe driver or by hand the transfusion should begin slowly at $0.25 \mathrm{ml} / \mathrm{kg} / \mathrm{h}$. If no adverse affects are encountered after the first 30-60 mins of administration the rate can be increased. Due to the urgency of the requirement for whole blood and any underlying concurrent disease the rate of administration can vary [75].

With a PCV of $20 \%$, dogs and cats with chronic anemia can be cardiovascularly stable [76]. Conversely in patients with an acute onset of anemia and continuing blood loss or hemolysis, transfusion to a higher PCV is necessary for stabilization. Generally administration of $2 \mathrm{~mL} / \mathrm{kg}$ of $\mathrm{WB}$ or $\mathrm{lmL} / \mathrm{kg}$ of pRBCs will increase the patient's PCV by $1 \%$ if there is no continuing hemorrhage or hemolysis [41].

Patient's overall condition determine the rate of blood administration. The maximum rate of transfusion is $10-20 \mathrm{~mL} / \mathrm{kg} / \mathrm{h}$ in normovolemic anemic patients, to avoid circulatory overload [41].

To provide blood volume again fluid therapy with crystalloids or colloids is necessary. If the patient's total blood volume do not decrease under $20 \%$ this is usually enough for losses. If losses are more than $20 \%$ whole blood or packed red cell transfusion is used. Between $20 \%$ and $50 \%$ of blood volume losses are treated by crystalloids and packed RBCs [3,77]. 
Blood components like cryoprecipitate and platelet-rich plasma are used infrequently. Cryoprecipitate contains vWF, factors VIII, XIII, fibrinogen, and fibronectin. In vWFdeficient patients cryoprecipitate is recommended particularly when surgery is planned or patient affected by blood loss. Bleeding hemophilia A patients, or patients having hypo or dysfibrinogenemia are the other indications for choosing it $[3,78]$.

Sometimes platelet-rich plasma is used in veterinary practice. In small-sized animals it is more useful because in larger dogs it is difficult to gain enough volume and management of platelet count. An alternative to platelet-rich plasma are frozen platelet concentrates [79].

For expansion of plasma volume, different types of colloids as dextrans and hetastarch are used as alternatives to blood products. Altering hemostasis is one of the problems of dextrans and hetastarch. Oxyglobin is a hemoglobin-based oxygen carrier. It is approved for use in the dog in 1998. In emergency situations it is used instead of blood products when there is limited time for preparing it or performing compatibility testing $[3,80]$.

In clinical signs of anaemia and as a therapy for carbon monoxide poisoning oxyglobin is used in cats. Because it is a potent colloid (colloid osmotic pressure $43 \mathrm{mmHg}$ ), the main risk associated with administration is volume overload. In patients with normovolaemic anaemia conservative administration rates are needed such as as low as $0.2-0.4 \mathrm{ml} / \mathrm{kg} / \mathrm{h}$ and to a maximum of $1 \mathrm{ml} / \mathrm{kg} / \mathrm{h}$. Careful monitorization of patients with paying particular attention to their heart and respiratory rate is recommended [81, 82].

A recent study described the clinical outcome in dogs experiencing massive transfusion. Also this study documented predictable changes in electrolytes and coagulation status. Massive transfusion is different from usual transfusions in terms of volume and rate of blood transfusion and blood components administered. Transfusion of a volume of whole blood or blood components has been described as massive transfusion. The administrated blood is greater than the patient's predicted blood volume within a 24-hour period or arranged as replacement of half the patient's predicted blood volume in 3 hours. In a study, massive transfusion receiving dogs were investigated and in this study the mean volumes of pRBCs was $66.5 \mathrm{~mL} / \mathrm{kg}$ and FFP was $22.2 \mathrm{~mL} / \mathrm{kg}$. As a result of this mean plasma, $\mathrm{RBC}$ ratio was 1:3. After transfusion clinicopathologic changes consists of electrolytes disturbances, dilutional coagulopathy, ionized hypocalcemia and hypomagnesemia and progressive thrombocytopenia and prolongation of prothrombin and activated partial thromboplastin times $[41,83]$.

\section{Preparations used for transfusions and blood transfusions indications}

The gold standard approach is that the donor and recipient are cross-matched before administration. Administration is maintained mainly intravascular with the use of peripheral or centrally placed catheter. Also intraosseous catheters can be used to administer all blood products. It is useful in collapsed neonatal patients where vascular access is difficult $[43,75,84]$. 
In acute hemorrhage, anemia, decreased red cell mass, severe methaemoglobinaemia, paracetamol toxicity, chronic non-regenerative anaemia, coagulation disorders, and thrombocytopenia fresh whole blood is used $[1,45]$.

The reason of anaemia in cats requiring transfusion are haemorrhage and primary immunemediated haemolytic anaemia. Hemorrhage is caused as a result of peri- or postoperative bleeding, trauma, gastrointestinal bleeding, abdominal neoplasia, primary immunemediated thrombocytopenia and coagulopathies $[85,86,87]$. Also in a number of infectious diseases anaemia is reported such as especially feline immuno-deficiency virus (FIV) and feline leukaemia virus (FeLV) infections, and feline infectious peritonitis [88, 89]. Other infectious diseases which cause anemia are Ehrlichia species, Bartonella species, Haemoplasmas (Mycoplasma haemofelis, 'Candidatus Mycoplasma haemominutum' and 'Candidatus Mycoplasma turicensis'), Anaplasma phagocytophilum, Neorickettsia risticii, Cytauxzoon felis and Rickettsia felis have additionally been associated with anaemia $[43,90]$.

The indication of whole blood is in a patient whom needed several blood components or has acutely lost more than $50 \%$ of its total blood volume. When $50 \%$ of total blood volume is lost oxygen carrying capacity and oncotic activity should be recovered. In anemia, stored whole blood is used. For anemic animals packed erythrocytes especially those with volume overload are prefered. For tissue reoxygenation the transfusion of packed RBCs are used. They are also useful for normovolemic, anemic patient. Before administration, to dilute any potentially damaging antibodies these erythrocytes can be washed with saline. Refrigerated whole blood should be warmed to room temperature. Before administration it sould be gently agitated to resuspend the red blood cells. Infusion rate is limited by colder blood which has a higher viscosity $[3,41,91]$.

The usage of transfusion of fresh-frozen or stored-frozen plasma (FFP) are as follows; lack of coagulation factors associated with hepatic insufficiency, disseminated intravascular coagulation (DIC), vitamin K deficiency, rodenticide toxicosis, liver insufficiency, biliary tract obstruction, sepsis/multiple organ dysfunction syndrome, pancreatitis, hypoalbuminemia, and DIC without associated laboratoryproven coagulopathy, malassimilation syndrome, chronic antibiotic use, a need for plasma volume expansion, or a massive blood loss within a few hours. Other It is also used in congenital or a hereditary deficiency in coagulation factors (i.e hemophilia A, B, or von Willebrand's disease and hypoproteinemia), [1, 3, 39]. Plasma (FP or FFP) is used especially in the emergency conditions like excessive protein loss such as enteropathy, nephropathy, exudative dermatitis or inadequate intake. It is not appropriate for using as long-term source of protein in these patients [3, 92]. In cats, reactions have not been reported following transfusions of FFP [46].

The collection and re-transfusion of the cat's own blood is called autotransfusion. It is a useful technique in an emergency situation. It can be obtained when animals bleed into body cavities. It should not be used if the blood is contaminated with urine, bacteria or bile. Blood is collected from the body cavity in a sterile manner. After that it re-transfused into 
the patient through an appropriate fitler. To prevent clotting anticoagulant like acid citrate dextrose should be included at a ratio of 1:7 [39, 43].

\section{Transfusions reactions}

The indication of transfusion reactions can be immunologic or nonimmunologic. They can be immediate or delayed. Antibodies to surface antigens of transfused erythrocytes cause immune-mediated hemolytic reactions. According to surface antigens canine blood is grouped. For six of these antigens typing is available. Except DEA 4, canine universal donor is negative for all dog erythrocyte antigens (DEAs). Universal donors should be examined. If other donors are known to be compatible with the recipient they can be also used. Acute hypersensitivities mediated by $\operatorname{IgE}$ antibodies are one of the possible immunologic reaction. The other can be leukocyte or platelet sensitivity caused by recipient antibodies to the donor's white cells or platelets. The mechanisms of nonimmunologic reactions are various. According to the specific reaction the type and severity of clinical signs vary [17] Adverse reaction occurs in 2 types. First one is immediate reaction and following transfusion it occurs within 1 to $2 \mathrm{~h}$. Second is delayed reaction and it may begin within days, months, or years later [17]. Adverse reaction varies from mild (fever) to severe (death). Transfusion reactions can be acute or delayed. In animals receiving incompatible transfusions, acute intravascular hemolysis with hemoglobinemia and hemoglobinuria may be seen. Acute hemolytic reaction is the most serious transfusion reaction that can be prevented. It is an immunological reaction and it happens when circulating natural or acquired antibodies towards donor erythrocytic antigens are given. Hemoglobinuria, vasoconstriction, renal ischemia occur due to intravascular hemolysis. Intravascular hemolysis determine clinical signs. Disseminated intravascular coagulopathy (DIC) can be caused by release of thromboplastic substances. Secondary to the release of vasoactive substances, hypotension and shock can ocur. Also acute renal failure and death can develop. After transfusion a decrease in hematocrit between 2 days and 2 weeks resulted in suspicion of delayed hemolysis. As a result of extravascular hemolysis, hyperbilirubinemia and bilirubinuria may occur. In dogs clinical signs are as follows: fever, tachycardia or bradycardia, hypotension, dyspnea, cyanosis, excessive salivation, tearing, urination, defecation, vomiting, collapse, opisthotonos, cardiac arrest, hemoglobinemia, and hemoglobinuria. When an acute hemolytic reaction occured transfusion sould be interrupted at once and shock should be treated. Also blood product being used sould be checked out and the steps that led to the transfusion sould be examined [1, 3, 17, 93].

To detect transfusion reactions earlier requires careful evaluation of patient's behavior, vital signs, and perfusion before, during, and after a RBC transfusion. Pre- and post-transfusion measurement of PCV and total solids for example instantly and at 24 hours are needed. Also evaluation of the plasma and urine for the presence of $\mathrm{Hgb}$ is done [41].

In the dog the acute hemolytic reaction is rare because in this species naturally occurring anti-erythrocytic antibodies prevalence is low [3]. Alloantibodies against the common canine erythrocyte antigens 1.1 and 1.2 do not exist in dogs. As a result of this generally first 
transfusion can be safely given without regard for donor blood type. Thus the recipient can be sensitized to immunogenic antigens (i.e 1.1, 1.2, 7, and others). On first transfusion it can cause shortened survival times of the transfused cells. Subsequent predisposition to severe transfusion reaction can develop. DEA 1.1 which is the strongest antigen in dogs, leads to the most severe transfusion reaction [1]. In the second transfusion especially when DEA-1 type blood is applied twice to a DEA- 1-negative dog there is more risk [3].

In cats receiving typed or crossmatched transfusions low rates of transfusion reactions have been indicated. Transfusions with whole blood or packed red blood cells transfusion reactions were reported [45]. But transfusions with FFP no reactions have been reported in cats [46].

Initial or subsequent $\mathrm{AB}$-mismatched transfusions in cats can cause acute hemolytic incompatibility reactions. Erythrocytes are destroyed immediately in cats because of alloantibodies. On the contrary in dogs, delayed transfusion reactions are more often occur. A type B transfusion to type A cat causes mild signs. In this situation shortened erythrocyte survival can occur. This causes ineffective therapy. Acute hemolytic transfusion reaction with massive intravascular hemolysis with serious clinical signs occurs in type A transfusion to a type B cat. These symptoms may occur even if it is the first transfusion. Type $\mathrm{AB}$ or $\mathrm{A}$ blood can be received by type $\mathrm{AB}$ cats safely $[1,94]$.

The transfusion should be stopped immediately if a transfusion reaction is suspected. The recipient sould be monitored continually for follow up. The most severe is acute haemolytic transfusion reactions developing as a result of naturally occurring alloantibodies [32].

Clinical signs are restlessness, vocalisation, tachypnoea, bradycardia, tachycardia, hypotension and hypertension. Pyrexia is seen frequently as a result of reactions to donor leukocytes, platelets and plasma proteins. As a result of binding by citrate, there is potential for hypocalcaemia when administering large volumes of blood products. Thus, if the patient is showing clinical signs of hypocalcaemia calcium should be measured [38, 43].

The next hour after transfusion nonhemolytic fever can ocur as adverse reactions. If contaminated blood products applied by mistake, fever may occur in an acute hemolytic reaction in association with septicemia. Vomiting or diarrhea can be seen after plasma administration. Rarely urticaria may cause trouble to patient. It can be treated with antihistamines, with or without glucocorticosteroids. If whole blood is administered with rapid administration of a large volume of blood component to normovolemic cats or smallsized dogs hypervolemia can be observed. Hypervolemia can result in pulmonary edema. Cough, tachypnea, dyspnea, or cyanosis can occur due to hypervolemia. Treatment can be done by stopping the transfusion, administering diuretics (furosemide) to reduce pulmonary edema, and providing oxygen support [3,72, 93].

The recipient should be carefully examined before the procedure. Its heart rate, respiratory rate, mucous membrane colour, capillary refill time and temperature sould be recorded. Also the PCV and total plasma protein should be recorded [43, 51] .

Delayed adverse transfusion reactions are consist of delayed hemolytic reaction, transmission of infectious disease, and posttransfusion purpura. Posttransfusion purpura 
has been reported in the dog. It is characterized by the appearance of severe thrombocytopenia in the week following a second transfusion. [3, 95, 96].

Anemia, regardless of underlying cause, is troublesome for clinicians in respect to stabilising and supporting the patient. The survival rate of all reasons for a transfusion is $84 \%$ in the first $24 \mathrm{~h}$. It is $75 \%$ for blood loss anaemia and $49.6 \%$ for ineffective erythropoeisis at 10 days $[43,97]$.

\section{Cross-Matching blood}

The incompatibilities between the donor's red blood cells and recipient's plasma are identified by major cross-match. The incompatibilities between the donor's plasma and recipient's red blood cells is identified by a minor cross-match [43].

Cross-Matching usually is identified as either "major" or "minor" cross-matches. A major cross-match include putting patient serum into donor cells and determine the presence of agglutinating and/or hemolytic antibodies in the patient aganist the donor antigens. The principle of this test is hemolytic or agglutinating reaction. In this test the reagent or antibody reacts with the RBCs. Serological discordance between a candidate donor and the patient is identified by the crossmatching. It does not determine the blood group [3]. A positive in vitro reaction is caused by the presence of antibodies. In patients that had no antibodies at the time of transfusion, a mild reaction can be seen in 4 to 14 days after mismatched transfusions. When blood is transfused to a patient in which antibodies are already present, a severe reaction occurs. This antibody can be developed by either naturally occurring or as a result of a previous mismatched transfusion. Furthermore, high concentrations of antibodies can be caused by isosensitization from transplacental immunization. In dogs that have received transfusions before, a crossmatch should always be performed. A minor cross-match include putting donor serum into patient erythrocytes. This step is not necessary for the donor whom previously tested negative for antibodies. Transfusing packed or washed erythrocytes rather than whole blood can prevent administration of antibodies in donor blood against patient erythrocytes [1].

Before transfusion the reason of analysis with these methods are to prevent acute hemolytic reaction due to transfusion, to provide optimal lifetime of the transfused RBCs, to prevent next discordant blood transfusions and to prevent neonatal isoerythrolysis [3].

Because there are blood types that have not been described and it is not possible to type for Mik it is recommended that cross-matching is performed before any transfusion. If the recipient has received a transfusion before more than 4 days cross-matching should be performed [98].

\section{Principles of blood transfusion in horses}

Horses have eight RBC groups or systems: A, C, D, K, P, Q, U, and T. The first seven systems are recognized by the International Society of Animal Blood Grouping Research. 
Blood-typing antiserum is not readily available for horses. Because of this to identify suitable donors equine blood-group testing can be performed by only few diagnostic laboratories. Over 30 different factors have been identified within these seven equine systems. Experimentally many more systems have been identified [99, 100]. Red cell antigens $\mathrm{Ca}, \mathrm{Aa}$, and $\mathrm{Qa}$ are play an important role in transfusion reactions and neonatal isoerythrolysis. There is no universal equine blood donor. Because of this to prevent inadvertent sensitization of brood mares against the two most common alloantigens (Aa and Qa) involved in neonatal isoerythrolysis, the preferred donor should be negative for factors $\mathrm{Aa}, \mathrm{Qa}$, and $\mathrm{Ca}[100,101]$. Aa and Qa alloantigens are most immunogenic, and most neonatal isoerythrolysis cases are associated with anti-Aa or Qa antibodies. The horse is clinically relevant for blood group incompatibilities. It is the only livestock species for this situation. Blood group antibodies can laed to transfusion reactions or NI and can be found in horses either "naturally" or as a result of a blood group incompatible pregnancy [2]. A donkey RBC antigen that has not been found in the horse has been identified, it is unique to the donkey and the mule [1].

In horses, requirement of blood transfusion include correction of anemia arising from acute blood loss secondary to trauma, surgical complications, ruptured uterine artery, guttural pouch mycosis, and neonatal isoerythrolysis $[99,102]$.

Generally, whole blood transfusions are applied to horses that have acute blood loss caused by trauma, surgery, or some other conditions like splenic rupture or uterine artery hemorrhage. The transfusion recovers blood volume and oxygen-carrying capacity in cases of blood loss. There is no certain indicative variables for the beginning of transfusion so that physical examination and clinicopathologic parameters should be used to make the transfusion decision. In cases of acute hemorrhage one sould remember that the packed cell volume (PCV) may be normal for up to 12 hours because of the time required for fluid redistribution and the effects of splenic contraction. As the horse is rehydrated with intravenous fluids, serial monitoring of PCV and total protein (TP) can estimate the amount of blood loss. The transfusion decision is made by suspection of large volume blood loss, together with tachycardia, tachypnea, pale mucous membranes, lethargy, and decreasing TP. During an acute bleeding episode when the PCV fall under $20 \%$, blood transfusion is probably required. In acute severe cases, transfusion may be required before there is a significant fall in PCV. PVC shows the need for beginning of transfusion in chronic anemia better whereas in acute hemorrhage, with transfusions proposed for horses with demonstration of tissue hypoxia and a PCV less than 10-12\% [103, 104].

Blood is collected and stored in glass bottles containing acid-citrate-dextrose (ACD). The method traditionally used for collecting blood from donor horses. Glass bottles containing ACD are easy and suitable for rapid vacuum blood draw. Because of this they are recommended for equine whole-blood collection. For equine whole blood the optimal storage method is commercial citrate-phosphate-dextrose with adenine (CPDA-1) bags [105, 106].

Packed RBCs (pRBCs) are specified for normovolemic anemia (i.e neonatal isoerythrolysis, erythropoietic failure, and chronic blood loss). Markers of tissue oxygenation, for example 
lactate and oxygen extraction are useful in chronic or hemolytic anemia cases. In horses, disseminated intravascular coagulation, clotting factor deficiency, hypoalbuminemia, decreased colloid oncotic pressure, and failure of transfer of passive immunity (FPT) are treated by plasma [104].

Colloid is usually used in patients with a total protein less than $4.0 \mathrm{~g} / \mathrm{dL}$ or serum albumin concentration less than $2.0 \mathrm{~g} / \mathrm{dL}$. When there is oncotic pressure less than $14 \mathrm{mmHg}$, clinical symptoms like ventral edema, and conditions which increase microvascular permeability like sepsis are other indications for colloid usage [104].

According to plasma obtained by plasmapheresis and centrifugation preparations, plasma prepared by gravity sedimentation contains greater numbers of erythrocytes and leucocytes. The risk of a transfusion reaction can be increased by these cells. During storage leukocytes can degranulate and fragment and release pyrogens and proinflammatory substances [107, $108,112]$.

Multiple hyperimmune plasma products are avaible with bacterial or viral specific antibodies. For the treatment of equine endotoxemia, the efficacy of E. coli (J5) and Salmonella tiyphiimiriuni hyperimmune plasma has proved to be useful in some reports; in contrast, there are some reports which disapprove the utility of such products. For the protection of R. equi, the use of Rhodococcus equi hyperimmune plasma has also been controversial. For treatment of specific disease additional plasma products like botulism antitoxin, West Nile virus antibody, and Streptococcus equi antibody are usable. In general equine practice plasma is administered to neonates to provide protective immunoglobulins. Protective immunoglobulins are used for treatment of failure of transfer of passive immunity or prophylaxis against Rhodococcus equi. Also, the albumin content of the plasma used as a colloid for circulatory volume support and in the treatment of proteinlosing enteropathies. In horses heritable and acquired coagulopathies can occur. Specific coagulation factors are not available for supplementation. Also indications include coagulopathies, protein-losing nephropathy and protein loss through third spacing into a body cavity (occurring with peritonitis or pleuritis) [104, 109-113].

Fresh frozen plasma must be separated and frozen within 8 hours of blood collection. Then it can be colder at $-18{ }^{\circ} \mathrm{C}$ and stored for up to 1 year. Frozen plasma is considered as plasma separated any time after 8 hours of blood storage [112, 114, 115].

\subsection{Blood donor selection}

Healthy, young gelding weighing at least $500 \mathrm{~kg}$ is the ideal equine blood donor. Donor horses should be performed current vaccinations. To prevent from equine infectious anemia donors should be tested each year. RBC antigens Aa and Qa are the most immunogenic antigens. Because of this in the ideal donor, the Aa and Qa alloantigens should be absent. There are breed-specific blood factor frequencies. Thus a donor of the same breed as the recipient, particularly when blood typing is absent may be preferable. Horses that have taken blood or plasma transfusions and mares that have had foals are not appropriate as 
donors. Because they have a higher risk of carrying RBC alloantibodies. Donkeys have a RBC antigen known as "donkey factor". Horses do not have this antigen. Thus donkeys or mules should not be used as donors for horses because horses can develop anti-donkey factor antibodies if transfusion takes place $[1,104,116]$.

An immediate blood transfusion can be applied for the first time in an emergency situation with a very minor risk of serious transfusion reaction. Horses can develop alloantibodies within 1 week of transfusion. Thus blood typing and crossmatching are recommended before a second transfusion is given. A second blood transfusion may be given confidently without a blood crossmatch within 2-3 days of the first transfusion. Blood typing and alloantibody screening can be used for the transfusion needed patient to find the most suitable donor horse. Blood typing and antibody screening before initial transfusion are more important for horses. Because subsequent blood transfusions are anticipated and if sensitized to other blood group factors broodmares may produce foals with neonatal isoerythrolysis (NI). For detection of equine RBC antigens $\mathrm{Ca}$ and $\mathrm{Aa}$, a rapid agglutination method has been developed. It can be more suitable for pretransfusion testing [99, 103, 104].

\subsection{Collection techniques}

Blood is collected from the jugular vein of the donor horse. For this purpose two way used; direct needle cannulation or catheteri-zation. When a large volume of blood is required, a 10 or 12 gauge catheter is recommended. A 14 gauge catheter is also sufficient. Plastic bags and vacum-collection glass bottles in sizes ranging from $450 \mathrm{~mL}$ to $2 \mathrm{~L}$ are suitable for blood accumulation. Anticoagulation with $3.2 \%$ sodium citrate is enough when blood is received for immediate transfusion. In saline-adenine-glucose-mannitol solution red blood cell concentrates stored and they can be used for transfusion for up to 35 days after blood accumulation. Equine blood storage condition resemble to canine and human blood storage condition. According to both in vitro tests and human parameters after 35 days of storage equine erythrocytes remain appropriate for transfusion. Fresh frozen plasma is obtained by separation of erythrocytes and plasma. Both of them can be used alone. RBC survival evaluation sould be doen in vivo [104, 117].

To allow separation of red blood cells by gravity sedimentation the blood is stored in a refrigerator at $5{ }^{\circ} \mathrm{C}$ for 48 hours in an upright position. Then the plasma is decanted into a sterile 3-L bag with sterile plastic connecting tubing using gravity. 3-L bags containes a constant weight of plasma $(3.4 \mathrm{~kg})$. The red cell fraction is thrown out. The plasma bags are sealed, labeled with the horse's name and the date of decantation. They are stored at $-20{ }^{\circ} \mathrm{C}$ until needed for plasma transfusion $[112,118]$.

\subsection{Administration}

In acute blood loss cases, PCV is usually impractical for estimation of volume to be transfused because it does not exactly indicate blood loss. Instead of this the volume of blood needed are predicted by estimation of blood loss and evaluation of clinical 
parameters. Fluid shifts will replace much of the circulating volume so between $25 \%$ and $50 \%$ of the total blood lost should be replaced by transfusion. Pay attention sould be give to that up to $75 \%$ of RBCs lost into a body cavity like hemoperitoneum are within 24-72 hours autotransfused back into circulation. Thus in cases of intracavitary hemorrhage lower percentages of blood volume replacement can be needed. To remove small clots and fibrin blood and plasma products should be given with an in-line filter [104, 119].

\subsection{Adverse reactions}

Blood should be given at a rate of approximately $0.3 \mathrm{~mL} / \mathrm{kg}$ over the first $10-20$ minutes for monitoring the transfusion reactions. Heart rate, body temperature, and respiratory rate sould be monitored. Additionally horses have to be monitored for signs of muscle fasciculation, piloerection, and urticaria. Urticaria, hemolysis, pruritis, edema, tachycardia, tachypnea, pyrexia, colic, changes in mentation and acute anaphylactic reactions are adverse reactions indicated in horses taking blood transfusions. The rate of adverse reaction to WB transfusion has been reported as $16 \%$ which are mild urticarial reactions and worsening hemolysis. Also 1 of 44 horses (2\%) exhibit a fatal anaphylactic reaction [103, 113].

Transfusion reactions may vary from mild urticarial reactions to anaphylaxis. They are divided into immunogenic and nonimmunogenic reactions. Immunogenic reactions include anaphylaxis, hemolysis, fever, hives, acute lung injury, posttransfusion purpura, immunosuppression, and neonatal isoerythrolysis. Nonimmunogenic reactions include circulatory overload, bacterial contamination, citrate toxicity, coagulopathy, hyperammonemia, and transmission of disease. In horses that have received fresh frozen plasma serum hepatitis has been observed $[52,93,112,120]$.

In a second plasma or blood transfusion there exists risk for severe adverse reactions in dogs. Also there is a risk of development of neonatal isoerythrolysis in gravid mares. The risk is much more in whole blood transfusions [26, 33, 112].

In horses suffered from normovolemic anemia polymerized ultrapurified bovine hemoglobin (PUBH) improves hemodynamics and oxygen transport parameters. During infusion to be informed about any adverse reactions patients should be monitored closely. Intense pruritus, tachycardia, and tachypnea can be resolved shortly after stopping the infusion [121].

\section{Principles of and indications for blood transfusion in ruminants and camelids}

Eleven blood groups have been classified in cattle. The greatest clinical relevance is in groups B and J. The B group is extremely complex, thus closely matched transfusions are very difficult. Newborn calves do not have the J antigen. During the first six months of life they generally acquire it. Cows can be sensitized to erythrocyte antigens by vaccinations of blood origin like some anaplasmosis and babesiosis vaccines. As a result of this neonatal isoerythrolysis in subsequent calves occur. [1]. 
Seven blood groups have been classified in sheep. The B group in these animals is resemble to the $\mathrm{B}$ group in cattle, and the $\mathrm{R}$ group is resemble to the J group in cattle. For example, antigens are soluble and soluble antigens passively absorbed to erythrocytes. In the goat, five blood groups are identified which resemble to those of sheep [1].

Blood group A-O expression is affected by 16 porcine blood groups and the $\mathrm{S}$ gene. Carbohydrate antigens like AO blood group antigens and minor histocompatibility antigens can be important targets for the immune response to transplanted organs or tissues. These antigens remain an unknown and untested variable in many transplant studies using pigs. Depending, on work performed in some Europian country pig blood groups developed and expanded largely. The source of blood typing reagents is especially from isoimmune sera. Most antibodies behave as agglutinins and a few as hemolysins. Internationally sixteen genetic systems are recognized [2, 122-124].

In two domestic South American camelids, Ilama and alpaca, our knowledge is little about group variation. Six blood groups factors were identified (e.g A, B, C, D, E and F) . from isoand heteroimmune sera constituted for these animals [2].

In ruminants and camelids indications for WB and plasma transfusion are similar to horses. Chronic anemia may be a more common problem in ruminants. Gastrointestinal parasites, particularly Haemonchus contains, and ectoparasites (e.g. Haematopinus spp. and Linognathus spp.) are causes of chronic blood loss anemia, and iron-deficiency anemia. These can affect neonatal calves [104, 121, 125].

Studies with camelids and bovines has showed that the neonatal intestine can only successfully absorb colostral immunoglobulins for 12-24 hours postpartum. Passive transfer (FPT) is failed in $19 \%$ to $24 \%$ of neonatal camelids. A common indication for plasma transfusion in neonatal calves and crias is failure of transfer of passive immunity. Hyperimmune serum products are existing for subcutaneous and intramuscular dosing in ruminants. These are products with antibodies against E. coli, Pasturella, Aercanobacter pyogenes, Salmonella typhimurium and Clostridium [104, 126-129].

An integral component of neonatal camelid care is IV plasma transfusion. It is used for the purpose of antibody supplementation and fluid resuscitation in critical illness. Neonates are immunocompetent at birth but due to initial postpartum absorption of colostrum for passive acquisition of immunoglobulins (especially $\operatorname{IgG}$ ) they are severely hypogammaglobulinemic $[130,131]$.

In cattle, the first blood transfusion should usually be safe, regardless of the donor. Jnegative donor is ideal. Because agglutination reactions do not develop, routine crossmatching is not useful in ruminants. First transfusions are usually safe to apply without a blood cross-match but crossmatching is recommended when more than 48-72 hours have passed away since the first blood transfusion. Blood donors should not have disease like bovine leukosis virus, anaplasmosis, and bovine viral diarrhea virus [104].

Total blood volume estimated in cattle is $80 \mathrm{~mL} / \mathrm{kg}$. From the donor animal up to $20-25 \%$ of total blood volume can be removed. Usually needle cannulation or jugular catheterization 
used in this situation. Blood can be collected into bottles or bags using citrate anticoagulant (e.g CPDA-1) in equine transfusions [104].

Blood samples can be taken from the jugular vein in sheep. A $500 \mathrm{ml}$ transfer bag system including a needle can use for the storage. These bags include $70 \mathrm{ml}$ of CPDA-1-stabiliser. Then the blood should be put into four $150 \mathrm{ml}$ transfer bags. These bags can be stored on a horizontal shaker. It shows the best preservation of platelet function. Also it can be used for the storage experiment consecutively [132].

Platelet count and aggregability of CPDA-1-stabilised ovine blood is kept most covenient at room temperature. It provides adequate haemostatic function for ex vivo experiments for one working day. In ovine blood functional loss and high percentage of platelets within aggregates can be observed at refrigerator temperature. This should be considered in blood transfusion in sheep [132].

\subsection{Administration and adverse reactions}

In order to monitor transfusion reactions blood should first be transported slowly. Ruminant blood type discordance result in primarily complement-mediated hemolysis. Volume overload should not be given. Also in neonates and small ruminants volume should carefully be given [104].

Intestinal absorption of antibodies declines sharply within the first 24 hours postpartum. For treatment of crias with failure of passive transfer (FPT) IV or intraperitoneal administration of $20-40 \mathrm{~mL} / \mathrm{kg}$ of camelid plasma is recommended. In compromised neonates requiring fluid resuscitation IV administration of plasma is generally preferred. It is used for the correction of FPT and colloid support. In foals during extensive plasma volume expansion careful monitoring is needed to prevent cardiopulmonary complications. Following IV plasma administration the cardiovascular and pulmonary effects of plasma volume expansion have not been specifically worked out in camelids. But in several species (i.e sheep and cat) plasma volume overexpansion depending on excessive IV fluid administration has been associated with reduced lung function and pulmonary edema formation in clinical and experimental settings. In addition according to measures in presumed hypovolemic human patients administration of colloids can induce a greater reduction in lung function than crystalloids [130, 133-137].

Measurable plasma volume expansion and a concurrent reduction in pulmonary functional residual capacity (FRC) is caused by IV administration of $30 \mathrm{~mL} / \mathrm{kg}$ camelid plasma to neonatal crias. In healthy neonatal crias administration of this quantity of plasma seems to be safe. But with underlying cardiopulmonary or systemic disease changes in lung volume associated with plasma administration could create risks for crias (131).

Adverse effects of transfusing blood stored for prolonged periods in lamps is encountered more often in patients with reduced vascular nitric oxide levels because of endothelial dysfunction. These patients can benefit from transfusion of fresh PRBC if available. Also 
inhaled nitric oxide supplementation can prevent pulmonary hypertension associated with transfusion of stored PRBC [138].

In previously untransfused pigs, hemolytic transfusion reactions do not appear to develop. But there have been two reports about adverse reactions in pigs undergoing liver transplants by the use of A-O incompatible transfusions. Pulmonary hypertension and decreased fibrinogen with an associated increase in fibrin degradation products occured in pigs that received A-O incompatible transfusions [139]. In a study, two pigs that administered $\mathrm{A}-\mathrm{O}$ incompatible blood transfusions during liver transplants died because of disseminated intravascular coagulation (DIC), bleeding and progressive hypotension [140].

\section{Conclusion}

Vital part of veterinary emergency and critical care medicine is transfusion medicine. It is also therapy of some disease of patient. Blood and blood products can be obtained through the purchase of blood products or donors. Potentially fatal adverse transfusion reactions risk is higher in cats than in dogs. Also, adverse transfusion reactions are very important for large animals. By using known donors and screening assays that permit detection of incompatibility of blood typing or crossmatching, the risk can be decreased in both species.

\section{Author details}

Nuri Mamak

Department of Internal Medicine, Faculty of Veterinary Medicine, University of Mehmet Akif Ersoy, Turkey

İsmail Aytekin

Department of Internal Medicine, Faculty of Veterinary Medicine, University of Balikesir, Turkey

\section{References}

[1] Brown D and Vap L. Principles of Blood Transfusions and Cross-Matching, In: Thrall, M.A., Baker, D.C., Campbell, T.W., DeNicola, D., Fettman, M.J., Lassen, E.D., Rebar, A., and Glade, W. (eds.) Veterinary Hematology and Clinical Chemistry. USA: Blackwell Publishing; 2006. p.197-202.

[2] Andrews GA and Penedo MC. Erythrocyte Antigens and Blood Groups. In: Weiss DJ and Wardrop KJ (eds.) Schalm's Veterinary Hematology (Sixth Edition). USA: Blackwell Publishing Ltd; 2010. p.711-724.

[3] Lanevschi A, Wardrop KJ. Principles of transfusion medicine in small animals. Can Vet J 2001;42 447-454.

[4] Hale AS. Canine blood groups and their importance in veterinary transfusion medicine. Vet Clin North Am (Small Anim Pract) 1995;25 1323-1332. 
[5] Symons M, Bell K. Expansion of the canine A blood group system. Anim Genetics 1991;22 227-235.

[6] Arikan, S., Guzel, M., Mamak, N, Ograk, Y.Z.: Frequency of blood types DEA 1.1, 3, 4, 5, and 7 in Kangal dog. Revue De Medecine Veterinaire 2009;160(4) 180-183.

[7] Gracner D, Bedrica L, Labura C, Maticic D, Gracner GG, Samardzija M. Blood groups and hematology in Istrian pointers. Vet Arhiv 2007;77 95-102.

[8] Ferreira RRF, Gopegui RR, Matos AJF. Frequency of dog erythrocyte antigen 1.1 expression in dogs from Portugal. Vet Clin Pathol 2011;40(2) 198-201.

[9] Ejima H, Kurokawa K \& Ikemoto S. DEA 1 blood group system of dogs reared in Japan. Jap J Vet Sci 1982;44 815-817.

[10] Andrews GA, Chavey PS, Smith JE. Production, characterization and applications of a murine monoclonal antibody to dog erythrocyte antigen 1.1. J Am Vet Med Assoc 1992;201 1549- 1552.

[11] Corato A, Mazza G, Hale AS, et al. Biochemical characterization of canine blood group antigens; immunoprecipitation of DEA 1.2, 4 and 7 and identification of a dog erythrocyte membrane antigen homologous to human Rhesus. Vet Immunol Immunopathol 1997;59 213-223.

[12] Swisher SL, Young NL. The blood group system of dogs. Physiol. Rev. (Baltimore) 1961;41 495-550.

[13] Novais AA, Fagliari JJ \& Santana AE. DEA (dog erythrocyte antigen) prevalence in domestic dogs (Canis familiaris) reared in Brazil. Ars Vet 2004;20 212-218.

[14] Colling DT, Saison R. Canine blood groups. 2. Description of a new allele in the $\mathrm{Tr}$ blood group system. Anim Blood Groups Biochem Genet 1980;11 13-2.

[15] Hohenhaus AE. Importance of Blood Groups and Blood Group Antibodies in Companion Animals. Transfusion Medicine Reviews 2004;18(2) 117-126.

[16] Andrews G.A. Red blood cell antigens and blood groups in the dog and cat. In Feldman BF, Zinkl JG and Jain NC (eds.). Schalm's Veterinary Hematology. Philadelphia: Lippincott Williams \& Wilkins; 2000. p.767-773.

[17] Harrell K, Kristensen A, Parrow J.: Canine transfusion reactions 1. Causes and consequences. Comp. Cont. Educ. Pract. Vet 1997;19 181-190.

[18] Hashimoto Y, Yamakawa T, Tanabe Y. Further studies on the red cell glycolipids of various breeds of dogs. A possible assumption about the origin of Japanese dogs. J Biochem 1984;96 1777-1782.

[19] Ejima H, Kurokawa K \& Ikemoto S. Comparison test of antibodies for dog blood grouping. Jpn J Vet Sci 1980;42 435-441.

[20] Ejima H, Nomura K \& Bull RW. Breed differences in the phenotype and gene frequencies in canine D blood system. J Vet Med Sci 1994;56 623-626.

[21] Ikemoto $S$ and Yoshida H. Genetic studies of new blood group C system on red cells of beagles. Jpn J Vet Sci 1981;43 429-431.

[22] Blais MC, Berman L, Oakley DA, et al. Canine Dal blood type: A red cell antigen lacking in some Dalmatians. J Vet Intern Med 2007;21 281-286. 
[23] Wardrop KJ. Clinical Blood Typing and Crossmatching. In: Weiss DJ, Wardrop KJ (eds.) Schalm's Veterinary Hematology (Sixth Edition). USA: Blackwell Publishing Ltd, 2010. p.1101-1105.

[24] Weinstein NM, Blais MC, Harris K, Oakley DA, Aronson LR, Giger U. A newly recognized blood group in domestic shorthair cats: the Mik red cell antigen. J Vet Intern Med 2007;21 287-92.

[25] Giger, U. Blood typing and crossmatching to ensure compatible transfusions. In: Kirk's Curr Vet Ther 2000; 13:396-399.

[26] Auer L \& Bell, K. The AB blood group system of cats. Animal Blood Groups, Biochemistry and Genetics 1981;12 287-297.

[27] Mylonakis ME, Koitonas AF, Saridomichelakis M, Leontidis M, Papadogiannakis M, Plevraki K. Determination of the prevalence of blood types in the non-pedigree feline population in Greece. Veterinary Record 2001;149 213-214.

[28] Griot-Wenk ME, Callan MB, Casal ML, Chisholm-Chait A, Spitalnik SL, Patterson DF and Giger $\mathrm{U}$. Blood type $\mathrm{AB}$ in the feline $\mathrm{AB}$ blood group system. American Journal of Veterinary Research 1996;57 1438-1442.

[29] Knottenbelt C.M. The feline AB blood group system and its importance in transfusion medicine. Journal of Feline Medicine and Surgery 2002;4 69-76.

[30] Arikan S, Duru SY, Gurkan M, et al. Blood type A and B frequencies in Turkish Van and Angora cats in Turkey. J Vet Med Ser A 2003;50 303-306.

[31] Arikan S, Gurkan M, . Ozaytekin E, Dodurka T \& Giger U. Frequencies of blood type A, $\mathrm{B}$ and $\mathrm{AB}$ in non-pedigree domestic cats in Turkey. Journal of Small Animal Practice 2006;47 10-13.

[32] Giger, U, Bucheler J. Transfusion of type-A and type-B blood to cats. J Am Vet Med Assoc 1991;198 411-418.

[33] Feldman BF. In-house canine and feline blood typing. J Am Anim Hosp Assoc 1999;35 455-456.

[34] Giger U, Gelens CJ, Callan MB, et al. An acute hemolytic transfusion reaction caused by dog erythrocyte antigen 1.1 compatibility in a previously sensitized dog. J Am Med Assoc 1995;206 1358-1362.

[35] Wilkerson MJ, Wardrop KJ, Meyers KM, et al. Two cat colonies with A and B blood types and a clinical transfusion reaction. Feline Pract 1991;19 22-26.

[36] Giger U, Bucheler J \& Patterson DF. Frequency and inheritance of A and B blood types in feline breeds of the United States. J Hered 1991;82 15-20.

[37] Casal ML, Jezyk PF, Giger U. Transfer of colostral antibodies from queens to their kittens. Am J Vet Res 1996;57 1653-1658.

[38] Griot-Wenk ME, Giger U. Feline transfusion medicine. Blood types and their clinical importance. Vet Clin North Am Small Anim Pract 1995;25 1305-1322.

[39] Rozanski E, de Laforcade AM, Transfusion Medicine in Veterinary Emergency and Critical Care Medicine. Clinical Techniques in Small Animal Practice 2004; 19(2) 83-87.

[40] Tocci LJ. Transfusion medicine in small animal practice. Vet Clin North Am Small Anim Pract 2010; 40(3) 485-494. 
[41] Callan MB. Red Blood Cell Transfusion in the Dog and Cat. In: Weiss DJ and Wardrop KJ (eds.) Schalm's Veterinary Hematology (Sixth Edition). USA: Blackwell Publishing Ltd; 2010. p.738-743.

[42] Hebert PC, Van der Linden P, Biro G and Hu LQ. Physiologic aspects of anemia. Crit Care Clin 2004;20 187-189.

[43] Barfield D, Adamantos S. Feline Blood Transfusions. A Pinker Shade of Pale. Journal of Feline Medicine and Surgery 2011;13 11-23.

[44] Michael MA, El Masry H, Khan BR, Das MK. Electrocardiographic signs of remote myocardial infarction. Prog Cardiovasc Dis 2007;50 198-208.

[45] Roux FA, Deschamps JY, Blais MC, Welsh DM, Delaforcade- Buress AM, Rozanski EA. Multiple red cell transfusions in 27 cats (2003-2006): indications, complications and outcomes. J Feline Med Surg 2008;10 213-218.

[46] Castellanos I, Couto CG, Gray TL. Clinical use of blood products in cats: a retrospective study (1997-2000). J Vet Intern Med 2004;18 529-32.

[47] Wardrop KJ, Tucker RL, Anderson EP. Use of an in vitro biotinylation technique for determination of posttransfusion viability of stored canine packed red blood cells. Am J Vet Res 1998;59 397-400.

[48] lseron KV, Mueslis DW. Blood warming: current applications and techniques. Transfusion 1991;31 558-569.

[49] Dodd R, Roth KW, Ashford P, Dax EM, Vyas G. Transfusion medicine and safety. Biologicals 2009;37 62-70.

[50] Godinho-Cunha LF, Ferreira RMRF, Silvestre-Ferreira AC. Whole blood transfusion in small animals: indications and effects. An Acad Bras Cienc 2011;83 (2).

[51] Chiaramonte D. Blood-component therapy: selection, administration and monitoring. Clin Tech Small Anim Pract 2004;19 63-67.

[52] Katz LM, Kiss JE. Plasma for transfusion in the era of transfusion-related acute lung injury mitigation. Transfusion 2008;48 393-397.

[53] Brooks MB. Transfusion of Plasma Products. In: Weiss DJ and Wardrop KJ (eds.) Schalm's Veterinary Hematology (Sixth Edition). USA: Blackwell Publishing Ltd; 2010. p.744-745.

[54] Berent AC, Todd J, Sergeeff J, Powell LL. Carbon monoxide toxicity: a case series. J Vet Emerg Crit Care 2005;15 128-135.

[55] Weingart C, Kohn B. Clinical use of haemoglobin-based oxygen carrying solution (Oxyglobin (R)) in cats: 48 cases (2002--2006). J Feline Med Surg 2008;10 431-38.

[56] Logan JC, Callan MB, Drew K, et al. Clinical indications for use of fresh frozen plasma in dogs. J Am Vet Med Assoc 2001;218 1449-1455.

[57] Lucas RL, Lentz KD, Hale AS. Collection and preparation of blood products. Clin Techn Small Anim Pract 2004;19 55-62.

[58] Vigano F, Perissinotto L, Bosco VR. Administration of 5\% human serum albumin in critically ill small animal patients with hypoalbuminemia: 418 dogs and 170 cats (19942008). J Vet Emerg Crit Care (San Antonio) 2010;20 237-243.

[59] Freireich EJ. Origins of Platelet Transfusion Therapy. Transfusion Medicine Reviews $2011 ; 25(3)$ 252-256. 
[60] Abrams-Ogg ACG. Plalet and Granulocyte Transfusion. In: Weiss DJ and Wardrop KJ (eds.) Schalm's Veterinary Hematology (Sixth Edition). USA: Blackwell Publishing Ltd; 2010. p.751-756.

[61] Segawa K, Kondo T, Kimura S, Fujimoto A, Kato T, et al. Effects of Prostaglandin E1 on the Preparation of Platelet Concentrates in Dogs. J Vet Intern Med 2012; 26 370-376.

[62] Callan MB, Appleman EH, Shofer FS, et al. Clinical and clinicopathologic effects of plateletpheresis on healthy donor dogs. Transfusion 2008;48 2214-2221.

[63] Hoffmeister KM, Felbinger TW, Falet H, et al. The clearance mechanism of chilled blood platelets. Cell 2003;112 87-97.

[64] Pruss A, Kalus U, Radtke H, et al. Universal leukodepletion of blood components results in a significant reduction of febrile non-hemolytic but not allergic transfusion reactions. Transfusion Apheresis Sci 2004;30 41-16.

[65] Slichter SJ, O'Donnell MR, Weiden PL, et al. Canine platelet alloimmunization: The role of donor selection. Br J Haematol 1986;63 713-727.

[66] Slichter SJ, Fish D, Abrams VK, et al. Evaluation of different methods of leukoreduction of donor platelets to prevent alloimmune platelet refractoriness and induce tolerance in a canine transfusion model. Blood 2005;105 847-854.

[67] Harris DJ The Resurgence of Granulocyte Transfusions. Journal of Infusion Nursing 2009; 32(6) 323-329.

[68] Christensen RD, Bradley PP, Priebat DA, et al. Granulocyte transfusion in septic canine neonates. Pediatr Res 1982;16 57-59.

[69] Head LL, Daniel GB, Becker TJ, et al. Use of computed tomography and radiolabeled leukocytes in a cat with pancreatitis. Vet Radiol Ultrasound 2005;46 263-266.

[70] Bashir S, Stanworth S, Massey E, et al. Neutrophil function is preserved in a pooled granulocyte component prepared from whole blood donations. BrJ Haematol 2008;140 701-711.

[71] Schneider A. Blood components. Collection, processing and storage. In: Kristensen AT, Feldman BF, (eds.). Canine and Feline Transfusion Medicine. Vet Clin North Am Small Anim Pract 1995; 25: 1245-1261.

[72] Hohenhaus AE. Blood banking and transfusion medicine. In: Ettinger SJ and Feldman AC (eds.) Textbook of Veterinary Internal Medicine, (5th ed. vol 1), , Philadelphia: WB Saunders, 2000. p.348-356.

[73] Tzannes S, Govendir M, Zaki S, Miyake Y, Packiarajah P, Malik R. The use of sevoflurane in a 2:1 mixture of nitrous oxide and oxygen for rapid mask induction of anaesthesia in the cat. J Feline Med Surg 2000;2 83-90.

[74] Killos MB, Graham LF, Lee J. Comparison of two anesthetic protocols for feline blood donation. Vet Anaesth Analg 2010;37 23039.

[75] Knottenbelt C, Mackin A. Blood transfusions in the dog and cat - Part 2. Indications and safe administration. In Pract 1998;20 191-199.

[76] Klaser DA, Reine NJ, Hohenhaus AE. Red blood cell transfusions in cats: 126 cases (1999). J Am Vet Med Assoc 2005;226 920-923. 
[77] Kristensen, A.T., Feldman, B.F., General principles of small animal blood component administration. In: Canine and Feline Transfusion Medicine, Kristensen AT, Feldman BF, Vet Clin North Am Small Anim Pract; 1995; 25: 1277-1290.

[78] de Gopegui RR, Feldman BF. Use of blood and blood components in canine and feline patients with hemostatic disorders. In: Canine and Feline Transfusion Medicine, Kristensen AT, Feldman BF, Vet Clin North Am Small Anim Pract., 1995; 25: 1387-1402.

[79] Abrams-Ogg ACG, Kruth SA, Carter RF, Valli VE, Kamel-Reid S, Dube ID. Preparation and transfusion of canine platelet concentrates. Am J Vet Res 1993;54 635-664.

[80] Kirby R and Rudloff, E. Fluid and electrolyte therapy. In: Ettinger SJ and Feldman AC (eds.) Textbook of Veterinary Internal Medicine. (5th ed. vol 1), , Philadelphia: WB Saunders, 2000. p.325-347.

[81] Adamantos S, Boag A, Hughes D. Clinical use of a haemoglobin-based oxygen-carrying solution in dogs and cats. In Pract 2005;27 399-404.

[82] Chan DL, Freeman LM, Rozanski EA, Rush JE. Colloid osmotic pressure of parenteral nutrition components and intravenous fluids. J Vet Emerg Crit Care 2001;11 269-273.

[83] Jutkowitz LA, Rozanski EA, Moreau JA, et aI. Massive transfusion in dogs: 15 cases (1997-2001). J Am Vet Med Assoc 2002;220 1664-1669.

[84] Corley EA. Intramedullary transfusion in small animals. J Am Vet Med Assoc 1963;142 1005-1006.

[85] Kohn B, Weingart C, Eckmann V, Ottenjann M, Leibold W. Primary immune-mediated hemolytic anemia in 19 cats: diagnosis, therapy, and outcome (1998-2004). J Vet Intern Med 2006;20 159-66.

[86] Culp WTN, Weisse C, Kellogg ME, et al. Spontaneous hemoperitoneum in cats: 65 cases (1994-2006). J Am Vet Med Assoc 2010;236 978-82.

[87] Wondratschek C, Weingart C and Kohn B. Primary immune-mediated thrombocytopenia in cats. J Am Anim Hosp Assoc 2010;46 12-19.

[88] Shelton GH, Linenberger ML, Persik MT, Abkowitz JL. Prospective hematologic and clinicopathological study of asymptomatic cats with naturally acquired feline immuno deficiency virus-infection. J Vet Intern Med 1995;9 133-140.

[89] Norris JM, Bosward KL, White JD, Baral RM, Catt MJ, Malik R. Clinicopathological findings associated with feline infectious peritonitis in Sydney, Australia: 42 cases (1990-2002). Aust Vet J 2005;83 666-673.

[90] Reynolds CA, Lappin MR. 'Candidatus Mycoplasma haemominutum' infections in 21 client-owned cats. J Am Anim Hosp Assoc 2007;43 249-257.

[91] Dula DJ, Muller HA \& Donovan JW. Flow rate variance of commonly used IV infusion techniques. J Trauma 1981;21 480-82.

[92] Koretz RL. Intravenous albumin and nutrition support: going for the quick fix. J Parenter Enteral Nutr 1995;19 166-171.

[93] Harrell KA, Kristensen AT. Canine transfusion reactions and their management. In: Kristensen AT, Feldman BF (eds.). Canine and Feline Transfusion Medicine. Vet Clin North Am Small Anim Pract 1995;25 1333-1364.

[94] Arikan S, Gurkan M. Kedilerde kan aktarımının klinik uygulama esasları. Ankara Üniv Vet Fak Derg 2009;56 153-157. 
[95] Lester SJ, Hume JB, Phipps B. Hemobartonella canis infection following splenectomy and transfusion. Can Vet J 1995;36 444445.

[96] Wardrop KJ, Lewis D, Marks S, Buss M. Posttransfusion purpura in a dog with hemophilia A. J Vet Intern Med 1997; 1(1) 261-263.

[97] Weingarta C, Gigerb U, Kohn B. Whole blood transfusions in 91 cats: a clinical Evaluation. Journal of Feline Medicine and Surgery 2004;6 139-148.

[98] Tocci LJ, Ewing PJ. Increasing patient safety in veterinary tranfusion medicine: an overview of pretransfusion testing. J VetEmerg Crit Care 2009;19 66-73.

[99] Owens SD, Joy Snipes K, Magdesian G, Christopher MM. Evaluation of a rapid agglutination method for detection of equine red cell surface antigens ( $\mathrm{Ca}$ and $\mathrm{Aa}$ ) as part of pretransfusion testing. Vet Clin Pathol 2008;37(1) 49-56.

[100] Mudge MC, Walker NJ, Borjesson DL, Librach F, Johns JL, Owens SD. Post transfusion survival of biotin-labeled allogeneic RBCs in adult horses. Vet Clin Pathol 2012;41(1) 5662.

[101] Bailey E. Prevalence of anti-red blood cell antibodies in the serum and colostrum of mares and its relationship to neonatal isoerythrolysis. Am J Vet Res 1982;43 1917-1921.

[102] Pusterla N, Fecteau ME, Madigan JE, Wilson WD, Magdesian KG. Acute hemoperitoneum in horses: a review of 19 cases (1992-2003). J Vet Intern Med 2005;19 344-347.

[103] Hurcombe SD, Mudge MC and Hinchcliff KW. Clinical and clinicopathologic variables in adult horses receiving blood transfusions: 31 cases (1999-2005). J Am Vet Med Assoc 2007;231 267-274.

[104] Mudge M.C. Blood Transfusion in Large Animals. In: Weiss DJ and Wardrop KJ (eds.) Schalm's Veterinary Hematology (Sixth Edition), USA: Blackwell Publishing Ltd 2010. p.757-762.

[105] Slovis NM, Murray G: How to approach whole blood transfusions in horses. Proc Am Assoc Equine Practnr 2001;47 266-269.

[106] Mudge M, Macdonald MH, Owens SD, Tablin F. Comparison of 4 Blood Storage Methods in a Protocol for Equine Pre-operative Autologous Donation. Veterinary Surgery 2004;33 475-486.

[107] Sachs UJH. The pathogenesis of transfusion-related lung injury and how to avoid this serious adverse reaction of transfusion. Transfusion Apheresis Sci 2007;37 273-282.

[108] Feige K, Ehrat FB, Kastner SBR, et al. Automated plasmapharesis compared with other plasma collection methods in the horse. J Vet Med 2003;50 185-189.

[109] Durando MM, MacKay RJ, Linda S, et al. Effects of polymyxin B and Salmonella typhimurium antiserum on horses given endotoxin intravenously. Am J Vet Res 1994;55 921-927.

[110] Perkins G A, Yeager A, Erb HN, et al. Survival of foals with experimentally induced Rhodococcus equi infection given either hyperimmune plasma containing R. Equine antibody or normal equine plasma. Vet Ther 2002;3 334-346.

[111] Feige K, Kastner SBR, Dempfle CE, et al. Changes in coagulation and markers of fibrinolysis in horses undergoing colic surgery. J Vet Med 2003;50 30-36. 
[112] Wilson EM, Holcombe SJ, Lamar A, Hauptman JG, Brooks MB. Incidence of Transfusion Reactions and Retention of Procoagulant and Anticoagulant Factor Activities in Equine Plasma. J Vet Intern Med 2009;23 323-328

[113] Hardefeldt LY, Keuler N, Peek SF. Incidence of transfusion reactions to commercial equine plasma. Journal of Veterinary Emergency and Critical Care 2010;20(4) 421-425.

[114] O'Neill EM, Rowley J, Hansson-Wicher M, et al. Effect of 24- hour whole-blood storage on plasma clotting factors. Transfusion 1999;39 488-491.

[115] Cardigan R, Lawrie AS, Mackie IJ, et al. The quality of fresh-frozen plasma produced from whole blood stored at 4 1C. Transfusion 2005;45 1342-1348.

[116] McClure JJ, Kock C, Traub-Dargatz J. Characterization of a red blood cell antigen in donkeys and mules associated with neonatal isoerythrolysis. Anim Genet 1994; 25:119120.

[117] Niinisto K, Raekallio M, Sankari S. Storage of equine red blood cells as a concentrate. The Veterinary Journal 2008;176 227-231.

[118] Eicker SW, Ainsworth DM. Equine plasma banking: Collection by exsanguination. J Am Vet Med Assoc 1984;185 772- 774.

[119] Sellon DC. Disorders of the hematopoietic system. In: Reed SM, Bayly WM. Sellon DC (eds.) Equine Internal Medicine, (2nd ed.). St. Louis: Elsevier 2004. p.728.

[120] Aleman M, Nieto JE, Carr EA, et al. Serum hepatitis associated with commercial plasma transfusion in horses. J Vet Intern Med 2005;19 120-122.

[121] Belgrave RL, Hines MT, Keegan RD, Wardrop KJ, Bayly WM \& Sellon DC. Effects of a polymerized ultrapurified bovine hemoglobin blood substitute administered to ponies with normovolemic anemia. J Vet Intern Med. 2002;16(4) 396-403.

[122] Andresen E. Blood groups in pigs. Ann N Y Acad Sci 1962;97 205.

[123] Hojny J, Stratil A. Report on the pig and sheep blood group and polymorphic protein workshops (Libechov, 9 to 11 August 1978). Anim Blood Groups Biochem Genet 1978;9 245.

[124] Smith DM, Newhouse M, Naziruddin B, Kresie L. Blood groups and transfusions in pigs. Xenotransplantation 2006;13 186-194.

[125] Fielding L. A hemoglobin-based oxygen carrier solution for the treatment of parasiteinduced anemia in a Barbados sheep. J Vet Emerg Crit Care 2006;16 54-57.

[126] Garmendia AE, Palmer GH, DeMartini JC, et al. Failure of passive immunoglobulin transfer: a major determinant of mortality in newborn alpacas (Lama pacos). Am J Vet Res 1987;48(10) 1472-1476.

[127] Weaver DM, Tyler JW, Scott MA, et al. Passive transfer of colostral immunoglobulin G in neonatal llamas and alpacas. Am J Vet Res 2000;61(7) 738-741.

[128] Barrington GM, Parish SM. Bovine neonatal immunology. Vet Clin North Am Food Anim Pract 2001;17(3) 463-476.

[129] Calloway CD, Tyler JW, Tessman RK, et al. Comparison of refractometers and test endpoints in the measurement of serum protein concentration to assess passive transfer status in calves. J Am Vet Med Assoc 2002;221 1605-1608.

[130] Wernery U. Camelid immunoglobulins and their importance for the new-born - a review. J Vet Med B Infect Dis Vet Public Health 2001;48(8) 561-568. 
[131] Paxson JA, Cunningham SM, Rush JE, Bedenice D. The association of lung function and plasma volume expansionin neonatalalpaca crias following plasma transfusion for failure of passive transfer. Journal of Veterinary Emergency and Critical Care 2008;18(6) 601-607.

[132] Baumgarten A, Wilhelmi M, Ganter M. Rohn K \& Mischke R. Changes of platelet function and blood coagulation during short-term storage of CPDA-1-stabilised ovine blood. Research in Veterinary Science 2011;91 150-158

[133] Dellinger RP, Levy MM, Carlet JM, et al. Surviving sepsis campaign: international guidelines for management of severe sepsis and septic shock: 2008. Crit Care Med 2008;36(1) 296-327.

[134] Palmer JE. Fluid therapy in the neonate: not your mother's fluid space. Vet Clin North Am Equine Pract 2004;20(1) 63-75.

[135] Bjorling DE \& Rawlings CA. Relationship of intravenous administration of Ringer's lactate solution to pulmonary edema in halothane- anesthetized cats. Am J Vet Res 1983;4(6) 1000-1006.

[136] Wallin CJ, Rundgren M, Hjelmqvist H, et al. Effects of rapid colloid volume expansion on pulmonary microvascular pressure and lung water in the conscious sheep. Respir Physiol 1997;108(3) 225- 231.

[137] Verheij J, van Lingen A, Raijmakers PG, et al. Effect of fluid loading with saline or colloids on pulmonary permeability, oedema and lung injury score after cardiac and major vascular surgery. Br J Anaesth 2006;96(1) 21-30.

[138] Baron DM., Yu B, Lei C, Bagchi A, Beloiartsev A et al. Pulmonary Hypertension in Lambs Transfused with Stored Blood Is Prevented by Breathing Nitric Oxide. Anesthesiology 2012;116 637- 647.

[139] Hunfeld MA, Hoitsma HF, Meijer S, van Haeringen H and Rietveld FW. The role of A-O-incompatible blood transfusions in porcine orthotopic liver transplantations. Eur Surg Res 1984;16 354.

[140] Sheil AG, Halliday JP, Drummond JM, Bookallil MJ, Gaudry PL, Yezerski SD. A modified technique for orthotopic liver transplantation. Arch Surg 1972;104 720. 